\title{
Sharing Responsibilities for Sustainable Development ${ }^{*}$
}

\author{
Cristiana Rogate ${ }^{* *}$
}

\begin{abstract}
The complexity and integrated nature of challenges for sustainable development call for a systemic approach based on commitment at all levels - individual, organizational and community - of all actors constituting the polis, that is, governments, business and civil society. The building of this innovative model of governance requires a methodology producing effective outcomes and changes. "Taking stock to report back" already tested in a large number of public and private organizations, has proven to be an effective methodology for strengthening any organization's culture on the issues of social and environmental sustainability and community engagement, methodology that can also be applied to build successful partnerships.
\end{abstract}

Keywords: Sustainability; Social Responsibility; Public-private Partnerships; Effectiveness; Common Good; Accountability; Web-Based Communication/Web Reporting; Global Markets

\section{Lack of Trust in Italy}

Trust is at the basis of any well-functioning democracy and its absence constitutes the core weakness of the Italian civic and political cultures.

If "men live upon trust", as John Locke argued, then Italians don't live well. The level of trust between citizens and institutions is the lowest in Europe, only second to Greece.

The Greek case, with the paralysis of the institutional, economic and social systems experienced over the last few years, well represents the dramatic consequences of the lack of trust as the fundamental unifying factor of a complex society.

Among Italian institutions, according to the Eurobarometer survey (table 1), Parliament, Government, Regional and local public authorities - constituting the check and balance system at the basis of democracy - show the lower level of trust than the UE average.

\footnotetext{
* Invited Article

** Founding partner and CEO of Refe, Strategies for Responsible Development (cristiana.rogate@refe.net)
} 
Table 1: Public Opinion in the European Union, May 2017* - Standard Eurobarometer 87 (Annex)

\begin{tabular}{|c|c|c|c|c|c|c|c|}
\hline Institution (May 2017) & IT & ES & FR & DE & UK & EU28 & $\begin{array}{l}\text { Difference } \\
\text { Italy-UE }\end{array}$ \\
\hline $\begin{array}{l}\text { Regional and local } \\
\text { public authorities }\end{array}$ & 23 & 32 & 57 & 74 & 52 & 51 & -28 \\
\hline Public administration & 23 & 33 & 57 & 55 & 54 & 45 & -22 \\
\hline $\begin{array}{l}\text { Government } \\
\text { (Nationality) }\end{array}$ & 17 & 18 & 38 & 55 & 36 & 37 & -20 \\
\hline $\begin{array}{l}\text { Parliament } \\
\text { (Nationality) }\end{array}$ & 19 & 18 & 31 & 58 & 36 & 36 & -17 \\
\hline United Nations & 36 & 45 & 48 & 47 & 55 & 49 & -13 \\
\hline $\begin{array}{l}\text { Justice/National legal } \\
\text { system }\end{array}$ & 43 & 37 & 56 & 65 & 66 & 55 & -12 \\
\hline Political parties & 11 & 7 & 10 & 35 & 15 & 19 & -8 \\
\hline Army & 68 & 75 & 88 & 63 & 81 & 74 & -6 \\
\hline European Union & 36 & 40 & 41 & 44 & 31 & 42 & -6 \\
\hline Police & 68 & 78 & 80 & 85 & 79 & 75 & -7 \\
\hline Large companies** & 57 & 58 & 52 & 48 & 50 & 54 & 3 \\
\hline $\begin{array}{l}\text { Small and medium- } \\
\text { sized companies } * *\end{array}$ & 68 & 89 & 87 & 89 & 84 & 83 & -15 \\
\hline Trade Unions** & 40 & 39 & 42 & 68 & 57 & 52 & -12 \\
\hline
\end{tabular}

Institutional and systemic trust, besides being an essential prerequisite for the proper functioning of democratic institutions, determines the degree of competitiveness of an economy as well as social cohesion.

We therefore need to work on multiple fronts for the growth of social trust in Italy. The primary responsibility for this change could only reside with Public Authorities, who establish the rules, values and behaviors affecting all members of the polis, both individual and collective, public and private.

For years, however, Public Authorities in our country have not been responsible at all: they have not been able to be accountable to their citizens for the trust they have been endorsed with, progressively eroding the legitimacy of Public Institutions, undermining the value of public goods, and limiting opportunities for growth and development.

\section{Responsibility across Sectors}

What does it mean "to be responsible"? "Being responsible for your own actions" is the most common definition. One of the most authoritative source, the Nicola Abbagnano's Dictionary of Philosophy, defines individual responsibility as "the 
possibility to foresee the consequences of our own behavior and correct it on the basis of this forecast". The Italian Civil Service Directive and related national Guidelines on social reporting for the Public Sector stated: "Each institution is responsible for its economic, social and environmental outcomes towards all stakeholders and the whole community".

Abbagnano calls consequences what the Directive defines as outcomes, that is, the changes produced by the implementation of public policies to the rights and needs of targeted stakeholders or the community in general.

And outcomes are what Public Authorities must be responsible for in order to act in accordance with their institutional mission. Hence, the need for Public Authorities to report back to their citizens on how the stated policy objectives have been achieved and produced value for the whole community. The Legislative Decrees $^{\mathrm{i}}$ implementing the Public Administration Reform Act (124/2015), reaffirmed the relevance of performance monitoring, reporting and assessment concept already introduced by the Law 150/2009 - through the direct involvement and participation of citizens and stakeholders.

While Public Authorities as labor and civil society organizations are innerly socially responsible, corporate social responsibility has been deeply redefined in the lights of some underlying shifts in the creation of economic value, clearly defined by Zadek (2006):

$\square$ "The historic increase in the importance of intangible assets as a value driver. Some of these assets, most significantly brand and broader reputation, are affected by how business deals with social and environmental impacts. The links between these impacts and valuecreating intangible assets are very real, but also quite complex. Significant brand damage through civil campaigning is a far less frequent occurrence than assumed in the media. Similarly, even where such damage does exist, its connection to market valuation (i.e., share prices) is weakened by the short-termism of the investment community, whereas many social and environmental issues impact only on longerterm business performance.

Public value as a growing source of economic value, with a growing proportion being located in businesses' delivery of public goods such as health, education, and policing, often through partnerships with non-commercial organizations. The implications of this are twofold. One is that businesses seeking to enter these sensitive markets have a far greater need to maintain a positive reputation. Second is that many business models in these markets depend on "nonmarket" engagements to extract commercially valuable knowledge and support, which again requires acceptable reputations.

The impact of the growth of the size and reach of individual businesses. This has the effect of enormously increasing the potential for externalities to strike back, and hurt. For example, the consolidation of the mining industry means that a reputational hit in one small site somewhere on the planet can impact on the entire reputation of the company, and so the profitability of its global operations. Interestingly, 
this raises the prospect of civil campaigning being most effective in relatively monopolistic markets, exactly where traditional analysis predicts the most likely damage to consumer interests.

$\square$ The changing communications environment, which further increases the potential for amplifying - both positively and negativelythe performance of one part of a business on the others, whether through corporate communications or civil campaigning. In particular, what has been termed by John Elkington as the "global fishbowl," has realigned the basis on which institutions and indeed individuals are brought to account, with "smart mobs" serving simultaneously as collective auditors and judges, while also taking it upon themselves to implement the punishment through brand and other forms of campaigns ${ }^{i i}$,.

In short, we can state that long-term economic sustainability within highly competitive and developed markets demands the enlargement of firms' responsibilities to include social and environmental impacts, making integrated responsibility necessary. The lively academic debate on Corporate Social Responsibility (CSR), Corporate Citizenship and Sustainability, and the emphasis currently placed on these concepts by national, international and supranational organisations - including the UN and the EU - has undoubtedly played a powerful role in the acknowledgment by societies of broader role for business ${ }^{i i i}$, and encouraged a growing number of corporations to embed social and environmental issues in their strategies, processes and behaviors.

Responsibility is a core cross-sectoral principle which can be applied to bring together, under a collaborative approach, organizations with different missions, cultures and strategies to enable sustainable development and the provision of common goods.

\section{Partnerships as a Key Pathway for Managing Complexity}

The complexity of global sustainability challenges highlights the limitation of individual approaches. Tackling them requires instead a systemic approach involving all actors constituting the polis, that is, governments, business, and civil society at all levels - individual, organizational and community (Gnecchi, 2004).

The last decades have seen an extraordinary growth in the number, size and scope of alliances, networks, and partnerships involving public and private actors as a key pathway for enabling sustainable development and the delivery of public goods. As attested by Zadek and Radovich (2006):

口 "multi-stakeholder and public-private partnerships are becoming a fundamental 'organizational building block' underpinning a growing array of activities seeking to mobilize and impact on diverse stakeholders in achieving a blend of public and private goals."

The United Nations also highlight the need to act in collaborative partnership to effectively implement the 2030 Agenda for Sustainable Development ${ }^{\mathrm{iv}}$ : 
$\square$ "We are determined to mobilize the means required to implement this Agenda through a revitalized Global Partnership for Sustainable Development, based on a spirit of strengthened global solidarity, focused in particular on the needs of the poorest and most vulnerable and with the participation of all countries, all stakeholders and all people. The interlinkages and integrated nature of the Sustainable Development Goals are of crucial importance in ensuring that the purpose of the new Agenda is realized. If we realize our ambitions across the full extent of the Agenda, the lives of all will be profoundly improved and our world will be transformed for the better. [...]

$\square$ The challenges and commitments identified at these major conferences and summits are interrelated and call for integrated solutions. To address them effectively, a new approach is needed. Sustainable development recognizes that eradicating poverty in all its forms and dimensions, combating inequality within and among countries, preserving the planet, creating sustained, inclusive and sustainable economic growth and fostering social inclusion are linked to each other and are interdependent."

Although multi-stakeholder alliances enable facing the complexity of sustainability challenges, this practice is also characterised by a high level of complexity. Their effective governance and the ways in which they can be hold accountable is, in fact, becoming equally a mainstream issue (Zadek, 2006).

As a consequence, it has recently emerged the need for a methodology to manage complexity and build successful partnerships capable of effectively tackle sustainability challenges.

\section{Integrated Methodology for Integrated CSR}

The methodology "Taking stock to report back" (Rendersi conto per rendere conto $^{\circledR}$ ) has been tested in a large number of public and private organizations, both at the individual and partnership levels, proving its value in managing complexity.

The defining characteristics of this methodology is the combination of the strategic and managerial dimensions with the communicative and participatory ones. "Taking stock" means assessing the identity of an organization, its values, choices, the work performed, the resources employed, and the economic, social and environmental performances and impacts. "To report back" moves from the results of this analysis to activate transparent, verifiable, and comprehensible communication processes and engage internal and external stakeholders for the evaluation of the created value.

This methodology enhances the effectiveness and responsibility of internal governance and management, as well as the credibility and reputation of the organization towards its stakeholders. It is based on the conceptual framework presented below (Figure 1) which engages all levels responsibility with asking the right questions for reconstructing the meaning and direction of the organization's mission, as well as assessing its social, economic and environmental impacts. Participation is, indeed, a key element of the framework for both the accuracy of the internal analysis and the independence of the evaluation. 
Figure 1: Conceptual Framework for Rebuilding the Sensus

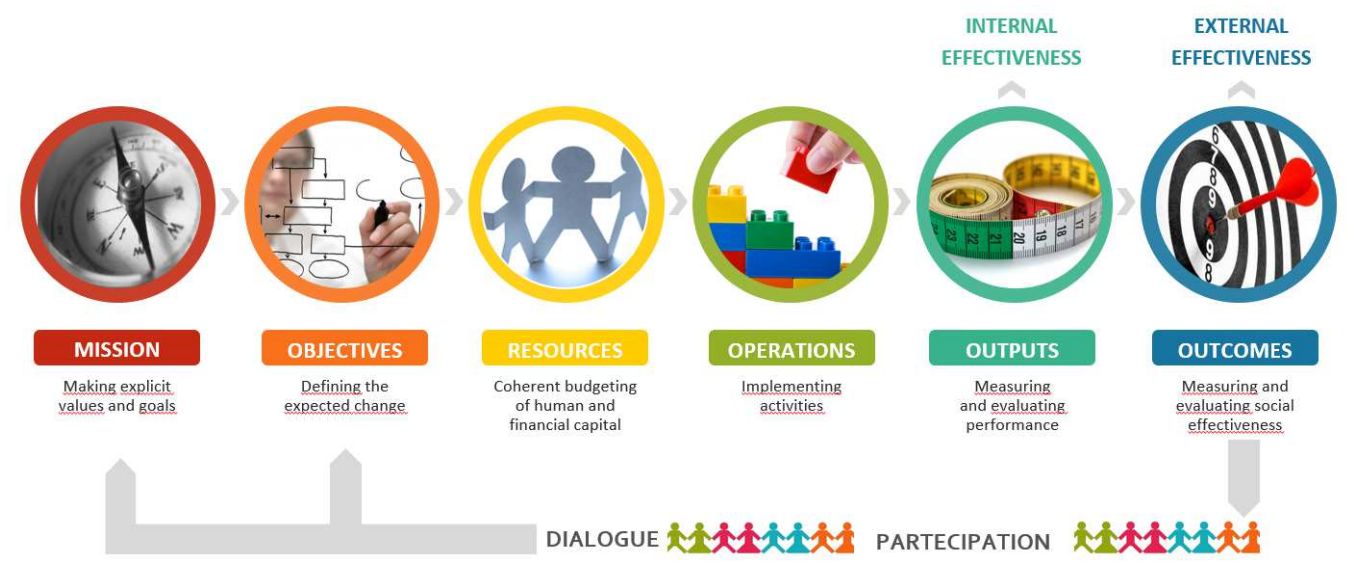

Refe

Source: Rogate \& Tarquini (2008)

This methodology improves a responsible management model, defined as the ability to answer:

- Coherently, to the organization's mission, founding values and strategies;

- Effectively, to several stakeholders' expectations,

- Transparently, about social, economic and environmental impacts.

The method is based on four key and strictly related phases, which are also essential for multi-stakeholder partnerships: (i) strategic planning, i.e. setting clear and verifiable targets; (ii) monitoring through the establishment of multidimensional Key Performance Indicators (KPIs); (iii) integrated reporting to measure and communicate performance in a clear and transparent manner; and (iv) engaging with stakeholders with a well-informed assessment of outcomes (Figure 2). 
Figure 2: Responsible Management Model

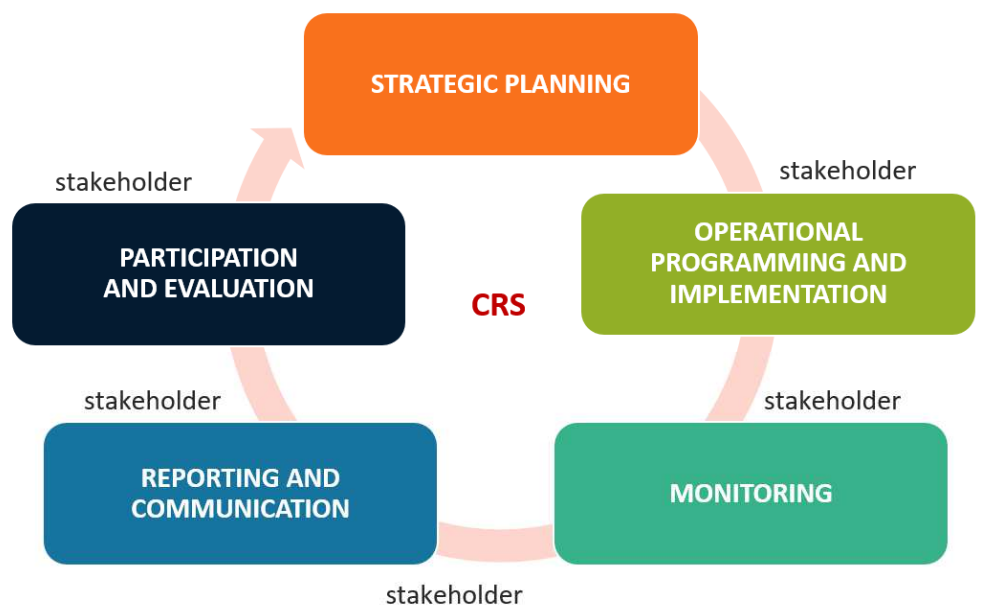

Refe

Source: Rogate \& Tarquini (2008)

First, it is crucial to strengthen a planning system that is not confined to the operational level (internal effectiveness), but that instead clearly identifies the strategic vision of an organization in terms of expected outcomes and changes achieved through its own operations for the improvement of social, economic and environmental wellbeing of communities (external effectiveness). The UN Sustainable Development Goals (SDGs) make a major contribution in this regard by setting common objectives expressed in terms of change (Figure 3). A roadmap for strategic partnerships should thus be embedded into all partners' strategic and operational plans and processes, assigning clear roles and responsibilities.

Figure 3: The UN Sustainable Development Goals (SDGs) ${ }^{v}$
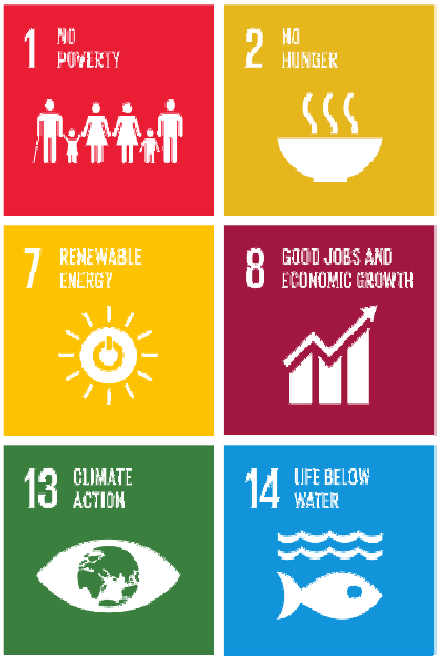
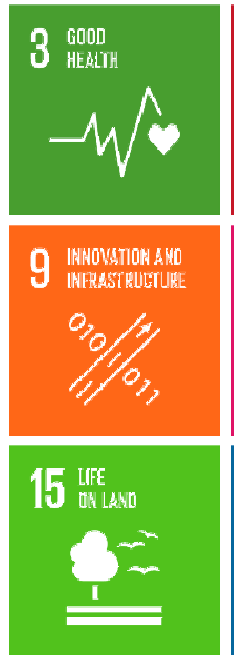
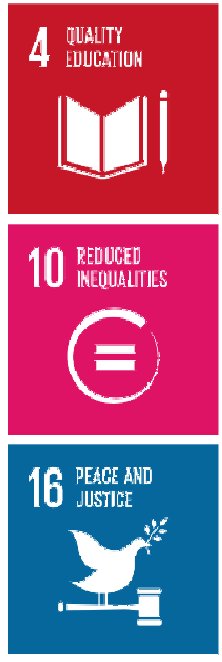
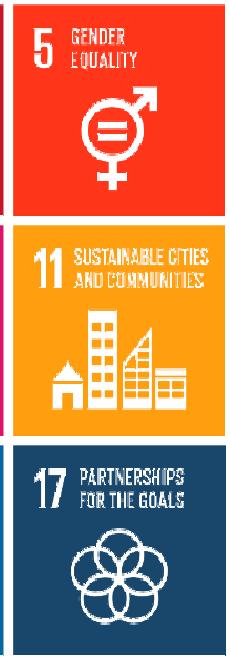
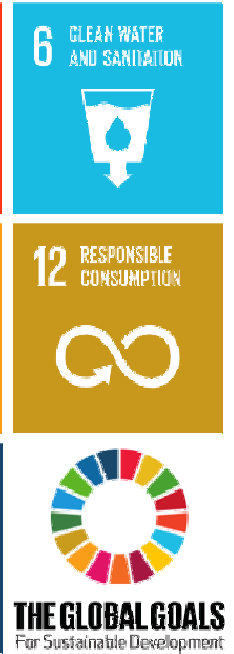

Second, monitoring is required to regularly check on the implementation of strategic plans, at both the individual and partnership levels, and measure progress. Monitoring requires the selection of multidimensional KPIs, reflecting the strategic 
and operational objectives of the organization, and their related targets and timetables. A key factor for adequate monitoring that is often not appropriately highlighted is the knowledge of the local economic, social, and environmental context at time $t_{0}$, which represents a conditio sine qua non for the establishment of the baseline against which monitor progress with the KPIs. Importantly, partnerships also constitute an asset for gathering a more comprehensive and reliable understanding of reality - which is complex and constantly evolving through the integration of different viewpoints and information. Finally, the systematic monitoring of activities improves the effectiveness of management and communication processes.

The third and fourth phases are highly interconnected. Proper planning and controlling of activities are basic requirements for a scientifically rigorous integrated reporting, which is, in turn, at the foundation of a credible and verifiable communication strategy for decision makers and stakeholders on the economic, social, and environmental performance of the organization. Sustainability or integrated reports constitute the informative basis for engaging the whole community into a positive and constructive dialogue, enabling learning and fostering trust between partners and stakeholders. The selection of meaningful indicators for external stakeholders and a broader audience is the key to satisfy the need of stakeholders for real information. This can be achieved by the constructive engagement of stakeholders both ex-ante and ex-post activities. On the one hand, the ex-ante engagement is important to assess the relevance of KPIs, share the context analysis, and strategic objectives. On the other, ex-post engagement allows to evaluate outcomes in a participatory fashion and readdress strategic planning, enhancing community commitment during implementation. Stakeholder engagement benefits from easy access to sustainability reports, issue that will be discussed later.

\section{Case History: "Varese Almost There" Project for a More Sustainable City and Community}

The case study sees the whole community engaged in increasing separate waste collection, on the basis of "Taking stock to report back" methodology.

\subsection{About Varese}

Varese is an Italian city with a population of about 81,000 people located in the north-west of the Lombardy Region. The city is the capital of the Province of Varese and the eighth most populous city of the Region. Similarly to the rest of the Province, Varese has a high immigrant population (about 10,000 people, corresponding to $12,3 \%$ of the population) due to its economy and its location. The centre is rich of places of historic and artistic interest. With its 62,000 companies and 377,000 employees/workers, the Province of Varese is one of the most industrialised areas in Northern Italy. Economic activities include services, trade, construction, industry, and agriculture.

ASPEM Varese Ltd. is a PPP multi-utility - employing around 300 workers providing different public services for the Municipality of Varese and others in the 
province area. Specifically, ASPEM is active in natural gas distribution, water and environmental services, including waste collection (Table 2).

Table 2: Services provided and Population Served by ASPEM

\begin{tabular}{|l|c|c|c|}
\hline Services & $\begin{array}{c}\text { Waste collection and } \\
\text { environmental services }\end{array}$ & $\begin{array}{c}\text { Water } \\
\text { service }\end{array}$ & Natural gas distribution \\
\hline $\begin{array}{l}\text { Population } \\
\text { served }\end{array}$ & 150.100 people & 221.000 people & 88.000 people \\
\hline
\end{tabular}

ASPEM controls $100 \%$ of Varese Risorse Ltd. - which manages the Varese district heating - and 12,47\% of Prealpi Sevizi LLC - which delivers water services to the two largest cities in the province: Busto Arsizio and Gallarate.

In January 2009, ASPEM Ltd. become part of the A2A Group - Italy's largest multi-utility. A2A acquired $90 \%$ of ASPEM Ltd. shares whereas the Municipality of Varese maintained control over around 9,8\% of them. Remaining shares are held by other small Municipalities of the Province. A2A is today the major Italian multiutility, the second national energy producer, the second operator of electricity networks, and one of the leaders in natural gas and water distribution. It is also leader in the market for environmental services and district heating.

\subsection{Defining Strategic Objectives}

In Varese, separate waste collection is a well-established practice that is, however, still in need of improvement. The percentage of separate waste collection was $61 \%$, four percentage points below the goal set by Lombardy Region.

In July 2016, ASPEM, in partnership with the Municipality, engaged in the communication and engagement project "Varese, almost there" targeted on the following strategic objectives:

- increasing the percentage of separate waste collection to reach the $65 \%$ goal set by the Lombardy Region by 2020 ;

- improving the quality of separate waste collection, identifying key implementing actors for the achievement of this sustainability goal.

As ASPEM Chairman stated at the press conference for the project start-up:

$\square$ "Separate waste collection in Varese is still increasing. The Regional goal of $65 \%$ by 2020 is within our reach. We are almost there. We believe that with everyone's support and collaboration we can reach it by next year."

\subsection{Main Leverages}

To achieve these goals, ASPEM decided to leverage on residents and city users' motivation to promote the adoption of adequate and responsible behaviours in waste management, reaffirming why separate collection is important and strengthening the sustainability culture, more and more focused on environmental respect and resource efficiency.

To ensure a long-term behavioural change, requesting compliance to the regional regulation is not sufficient. It is fundamental to motivate everyone's change within 
a logic of co-responsibility, explaining the effects produced by proper or improper practices in resource management on environmental protection for future generations and familiar economic savings. For these reasons, the project is developing at two levels:

- communication - to increase citizens' awareness;

- stakeholder engagement - to improve community's motivation and commitment in the implementation of the sustainability goals.

The communication campaign started in September 2016 with the delivery of a "waste collection kit" to all families and traders. Furthermore, the main means of communication used in the campaign were:

- posters;

- advertising on ASPEM website and the most used local media websites;

- customized waste collection calendars for each of the 42 city areas;

- customized bread bag for families with campaign's images and recipes against food waste;

- stickers for condominium where separate waste collection is mismanaged.

- The case study now focuses on stakeholder engagement process to highlight the lessons learned for ensuring quality and effectiveness of partnerships.

\subsection{Implementing Stakeholder Engagement}

The engagement process started after the launch of the communication and awareness-raising campaign and involved the three target groups with most critical conduct, in particular: building managers, city centre residents and traders and associations of immigrants. It was designed to:

- inform each target group about specific waste management process, including steps, timetables, rules and methods of collection, roles and responsibilities of all parties involved, main weaknesses and relative shared solutions,

- clearly communicate the multidimensional benefits produced by the adoption of correct and sustainable behaviours;

- make every actor responsible for its own contribution to the achievement of common goals;

- strengthen a constructive and informed dialogue between ASPEM and its customers.

Figure 5: ASPEM Stakeholder Engagement Phases

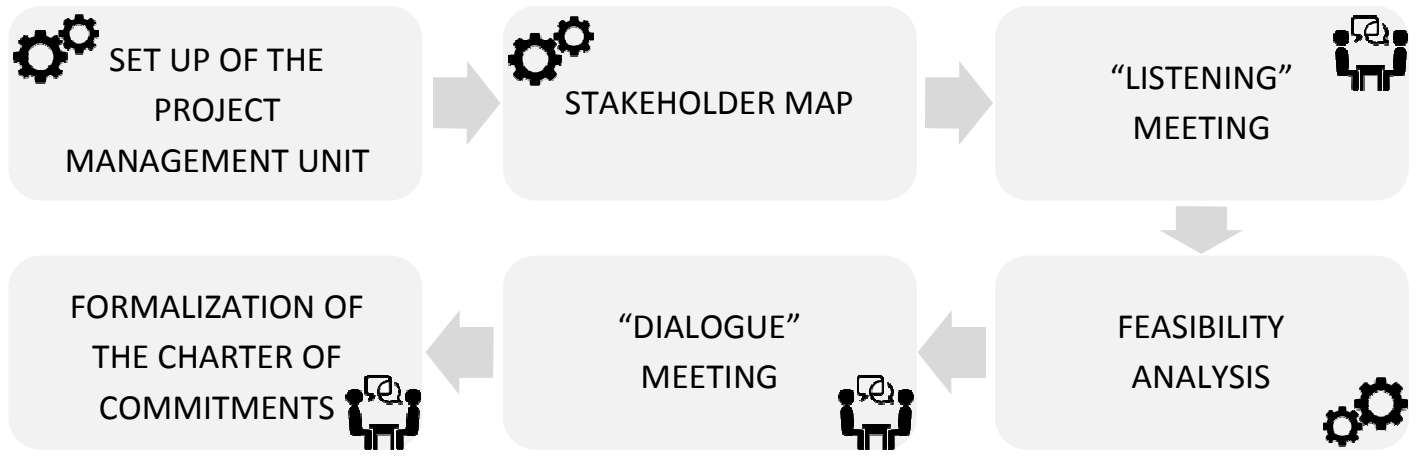


The most relevant activities were:

\section{Set up of the Project Management Unit}

First, the Unit was set up for steering and monitoring the project, integrating institutional actors responsible for the delivery of public goods into the decisionmaking process, that is:

- ASPEM: Chairman, CEO and Communication Director

- Municipality of Varese: Major and Councillors for Environment, Social Policies and Trade.

\section{Stakeholder map}

Relevant community stakeholders were mapped to identify all the actors belonging to the three target groups, stressing the already established relationships with ASPEM and the Municipality.

Stakeholders - engaged within a logic of partnership - played a fundamental role in encouraging the activation of local networks and disseminating the results of the engagement, hence improving project's effectiveness. The stakeholder map is an useful output per se: it is now adopted, especially by the Municipality of Varese, to support the implementation of other public policies and open new participation pathways.

\section{Stakeholder meetings}

Three focus groups were organized, one for each target group - building managers, residents and traders of the city centre, and associations of immigrants - over two meetings.

The participants to first meeting were introduced to:

- strategic project objectives and activities;

- ASPEM mission, activities and performances;

- specific waste management process tailored to each target group, highlighting inadequate behaviours to be corrected.

The first meeting was focused on listening: for every single step of waste management process - as shown in figure 6 - participants individually pointed out observations and critical issues, which were clustered on the spot.

Figure 6: ASPEM Waste Management Process

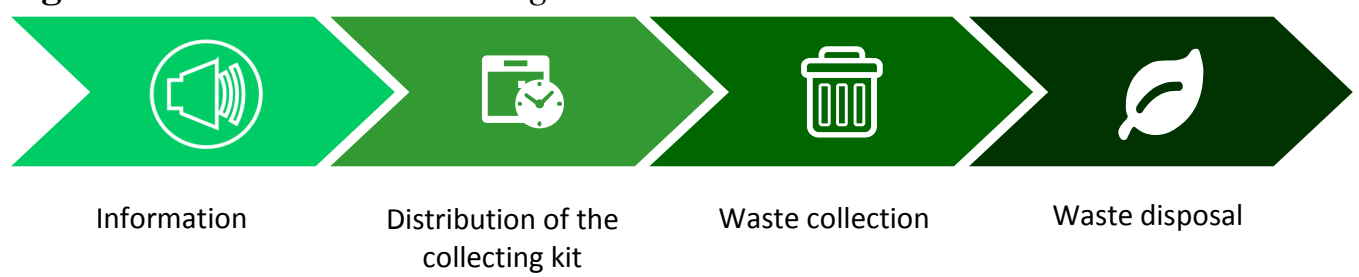

For each cluster, participants proposed shared solutions, which were then evaluated by ASPEM together with the Municipality within a feasibility analysis conducted to draft practical answers to the issues highlighted by the stakeholder.

The second meeting made room for discussion and mutual learning among ASPEM, the Municipality, and stakeholders, clarifying waste management responsibilities and proposing shared solutions to the weaknesses outlined for each 
step of the waste management process. The issues emerged led to the drawing of the "Charters of Commitments".

\subsection{Charters of Commitments for Sharing Responsibilities}

The Charter of Commitments presents observations and critical issues on waste management processes, the solutions proposed by stakeholders and ASPEM and the Municipality's answers for each target group. These answers are provided in terms of information on waste collection services - reducing information asymmetry commitments made by ASPEM, the Municipality of Varese and stakeholders and, finally, commitments to be made after a technical verification.

With respect to already existing commitments, the Charter assigns clear roles and schedules activities. The three versions of the Charter have been signed by all actors involved in the presence of the press, to give official nature and make known this agreement to all citizens.

The Charter of commitments represents a point of departures rather than an end. It relaunches the community's commitment towards sustainability goals, structuring a systematic and stable partnership between citizens and institutions. This collaborative arrangement proves how much each partner's commitment and welldefined contribution is essential for partnership's effectiveness, within the logic of sharing responsibilities.

The Charter helps aligning individual commitments and their staying on track towards common objectives and defines a shared roadmap to address behaviour. It enables a responsible, credible and measurable changing process, that opens a larger community engagement with the involvement of new stakeholders, starting from city schools, potentially intercepting up to three generations: students, parents and grandparents. As requested by the Focus Groups, stakeholder engagement was extended in the second year of the project to all schools in Varese for both educational purpose, enhancing a sustainability culture, and a broader dissemination of the communication campaign contents.

This innovation required the enlargement of the Project Management Unit to include the Council Member for Education, A2A, and COMIECO i.e. the National Consortium for the Recovery and Recycling of Cellulose-based Package. School leaders, teachers, and student representatives were invited to provide their observations, present critical issues, as well as proposals to improve separate waste collection in each school. The two meetings led to a new Charter of Commitments, signed by all schools. In addition, thanks to A2A and COMIECO participation, a pilot project to increase information and improve separate waste collection by recycling facilities with special containers in middle schools was planned.

In line with the project mutual approach, one of the main commitment requested the creation of a Task Force in each school, as a stable reference point for communication on separate waste collection.

\subsection{Follow-up, Monitoring and Accountability}

The subscription to the Charter triggered the implementation of planned actions, specifically:

- Recycling facilities with special containers in middle schools, 
- ASPEM's employee engagement and training to improve service delivery and customer relations, tackling the critical issues emerged in these areas during the engagement process;

- Preparation of customized guidelines for the now four target groups, building managers, city center residents and traders, associations of immigrants and schools.

As concerns monitoring, follow-up meetings were planned every six months to check and measure the implementation of everyone's commitments. This led to precise and transparent progress reporting on separate waste collection.

This case study shows some fundamental elements of the "Taking stock to report back" methodology, highlighting its effectiveness. The "Taking stock" phase involved the analysis of the context to define the expected changes and identify the key actors to be involved to make this change happen in a co-responsibility logic. Participation qualified the internal analysis, enabling a more comprehensive understanding of the local context for the co-design of strategic objectives and the definition of a shared action plan. Ongoing monitoring of progress achieved by all actors in the implementation of commitments, through smart and inclusive reporting instruments, is now fundamental. The case study also highlights the importance of a strong connection between the managerial and the communication dimensions. Participation stressed some critical issues, setting new strategic objectives to improve internal management. Reporting and communication of such improvements help strengthen the partnership established with the stakeholders, enhancing the credibility and effectiveness of the organisation and the partnership.

\section{Accountability and CSR Integrated Web-Based Communication}

Accountability is, indeed, a key element to improve partnership's effectiveness. Currently, integrated or sustainability report is a widespread form of reporting in different types of organizations at the international level, emerged to satisfy the information needs of different stakeholders (Van Marrewijk, 2003; Montiel, 2008; Salvioni \& Bosetti, 2014).

The European Union ${ }^{\text {vi }}$ introduced in 2014 the obligation for European large public-interest entities and groups to produce non-financial statements and integrate them into their management reports or, alternatively, to provide a separate report including information on the entity's development, performance and impact. Individual companies or groups exceeding 500 employees are required to disseminate information on environmental, social and employee-related matters, and anti-corruption rules.

Based on the large body of literature on accountability, and more than 20 years of the Author's experience on the field, sustainability reporting produces the expected benefits on the strategic and managerial dimensions, improving the quality of governance - clearly addressing decision-making and implementation processes encouraging innovation, and strengthening internal motivation. The main limit concerns the external dimension, especially the ability to communicate in a clear and transparent manner the organization's identity and performance to all relevant stakeholders, fostering trust and reputation, which is a key objective of accountability. 
In some instances, reporting back to stakeholders becomes a bureaucratic exercise involving the adoption of standard and/or generic and self-congratulatory communication messages, not backed by data relevant to stakeholders, progressively reducing the credibility of the organization.

Digitization and web based-communication open new scenarios in the accountability processes (Lambin, 2014) helping to overcome this communication, enforcing the logic of transparency within organizations (Bebbington, Unerman, O'Dwyer, 2014). In particular, web reporting is a real-time tool - linked or integrated into the corporate website - creating a virtuous relationship amongst communication, accountability, open data, and stakeholder dialogue. It represents a clear information platform, accessible, and designed to meet the information needs of stakeholders interested in learning about the organization, its strategies and economic, social and environmental performances (GBS Guidelines, 2017).

As an example of the increasing centrality of this issue, the Italian Association for Scientific Research on Social Accountability (GBS) organized (following suggestion of the Author) a research team dedicated to web reporting, including 22 Italian Universities. The research team published in July 2017 a paper titled: "Web reporting as a new frontier for accountability. Guidelines." The paper has been presented in October during the National Edition of CSR and Social Innovation Expo at Bocconi University, Milan.

The adoption of web reporting represents a Copernican revolution in accountability practices, although the use of the web channel cannot be limited to the upload of reports, but goes rather far beyond, unlocking several opportunities:

- Iterative reporting (vs. ex-post): improves usage, timeliness and relevance of data and information;

- Relevance and effectiveness of contents: makes reporting smart, interesting and appealing, allowing for a personalized display of information with different levels of analysis and targeted inquiries;

- Engagement and interactivity: facilitates a timely and interactive dialogue on identity, strategy and performance, useful both to the organization and its stakeholders, facilitating mutual learning and co-operation;

- Efficiency and sustainability: promotes cost-effective outreach to a broad audience and with limited environmental impact.

Web reporting reinforces a culture based on transparency, information, and evaluation of changes within any kind of organization, public and private. It realigns internal management and communication practices, which are often inconsistent with the overall business strategy, missing the opportunity to strengthen the organization's capital of credibility and trust (Rogate, Tarquini, 2008).

\section{Conclusions}

Sustainable development has emerged as a crucial issue. Indeed, we are seeing the proliferation of objectives, initiatives and rules regarding sustainability at all levels - local, national and international - that together with a lively academic debate, has 
led to considerable progress in public and private organizations taking on wider responsibilities with a stronger commitment on social, economic and environmental challenges.

However, each actor is acting in isolation rather than within a systemic approach, which is the only way to effectively tackle sustainability challenges.

To overcome this critical limit, the methodology "Taking stock to report back" ("Rendersi conto per rendere conto ${ }^{\circledR, ")}$ can help. This is particularly true in the Italian context, currently challenged by a trust crisis and a weak civic culture. This methodology for responsible management model enhances - internally - the integrated organization's responsibility and - externally - transparency and disclosure towards all relevant stakeholders and the whole community. Accountability plays a fundamental role in strengthening the ability to measure and communicate performance in a clear and transparent manner, which is at basis for activating a systematic dialogue.

Accountability, supported by digitization, has the potential to drive a cultural change within individual organizations and, hence, between organizations, supporting shared responsibilities for sustainability development as well as the preservation of the common good.

\section{Acknowledgement}

I really thank Valentina Pericoli e Margherita Pennati, Refe Senior Consultants for their support.

\section{Bibliography}

Bebbington, J., Higgins, B., \& Frame, B. (2009). Initiating sustainable development reporting: evidence from New Zealand. Accounting, Auditing \& Accountability Journal, 22(4), 588-625, Emerald Group Publishing Limited

Bebbington, J., Unerman, J., \& O'Dwyer, B. (2014). Sustainability accounting and accountability. Routledge, Abingdon.

Bellinger, A., Ball, A., \& Craig, R. (2011). Reasons for sustainability reporting by New Zealand local governments. Sustainability Accounting, Management and Policy Journal, 2(1), 126-138, Emerald Group Publishing Limited.

Bisio, L. (2006). Public Governance and Financial Communication. Symphonya. Emerging Issues in Management (symphonya.unimib.it), 1, 110-128.

http://dx.doi.org/10.4468/2006.1.08bisio

Bovens, M. (2007). Analysing and assessing accountability: a conceptual framework. European Law Journal, 13(4), 447-468.

Brondoni, S.M. (2000-2001), Brand Policy and Brand Equity. Symphonya. Emerging Issues in Management (symphonya.unimib.it), 1, 5-25.

http://dx.doi.org/10.4468/2001.1.02brondoni

Donaldson, T., \& Preston, L. E. (1995). The stakeholder theory of the corporation: Concepts, evidence, and implications. Academy of management Review, 20(1), 65-91.

European Commission, Directorate-General for Communication, (2016). Public opinion in the European Union, Standard Eurobarometer, 85 (Annex)

https://ec.europa.eu/commfrontoffice/publicopinion/index.cfm/Chart/index 
European Commission, Directorate-General for Communication, (2017). Public opinion in the European Union, Standard Eurobarometer, 87 (Annex)

https://ec.europa.eu/commfrontoffice/publicopinion/index.cfm/Chart/index

Freeman, R. E., Harrison, J. S., Wicks, A. C., Parmar, B. L., \& De Colle, S. (2010). Stakeholder theory: The state of the art. Cambridge University Press.

GBS (2017), Le nuove frontiere della rendicontazione sociale: il Web reporting. Linee di orientamento. Documenti di ricerca n. 14 ["Web reporting as a new frontier for accountability. Guidelines. Research paper No. 14”]. Franco Angeli Editore, Milan.

Gnecchi, F. (2004). Relations between Local Authorities and Public Utilities Companies. Symphonya. Emerging Issues in Management (symphonya.unimib.it), 1, 58-68.

http://dx.doi.org/10.4468/2004.1.06gnecchi

Gray, R. (2002). The social accounting project and Accounting Organizations and Society Privileging engagement, imaginings, new accountings and pragmatism over critique? Accounting, organizations and society, 27(7), 687-708.

Lambin, J.-J. (2014). Rethinking the Market Economy. Symphonya. Emerging Issues in Management (symphonya.unimib.it), 2, 4-15.

http://dx.doi.org/10.4468/2014.2.02lambin

Messner, M. (2009). The limits of accountability. Accounting, Organizations and Society, 34(8), 918-938.

Montiel, I. (2008). Corporate social responsibility and corporate sustainability separate pasts, common futures. Organization \& Environment, 21(3), 245-269.

Mulgan, R. (2000). 'Accountability': An Ever-Expanding Concept?. Public administration, 78(3), 555-573.

Parker, L. D. (2005). Social and environmental accountability research: A view from the commentary box. Accounting, Auditing \& Accountability Journal, 18(6), 842-860.

Rogate C., \& Tarquini T. (2004), Il bilancio sociale negli enti locali. Scenario, metodologia ed esperienze [Social report in local public authorities]. Maggioli Editore, Rimini.

Rogate C., \& Tarquini T. (2008), Fiducia e responsabilità nel governo dell'Ente pubblico. Il Bilancio sociale per le Pubbliche Amministrazioni Territoriali [Trust and responsibility in public governance. Social report in Regional and local public authorities]. Maggioli Editore, Rimini.

Salvioni, D.M., \& Bosetti, L. (2014). Sustainable Development and Corporate Communication in Global Markets. Symphonya. Emerging Issues in Management (symphonya.unimib.it), 1, 32-51. http://dx.doi.org/10.4468/2014.1.03salvioni.bosetti

United Nations (2015). Transforming Our World: The 2030 Agenda for Sustainable Development.

Van Marrewijk, M. (2003). Concepts and definitions of CSR and corporate sustainability: Between agency and communion. Journal of business ethics, 44(2-3), 95-105.

Zadek, S. (2006). The Logic of Collaborative Governance: Corporate Responsibility, Accountability, and the Social Contract. Corporate Social Responsibility Initiative, Working Paper No. 17, Cambridge, MA: John F. Kennedy School of Government, Harvard University

Zadek, S., \& Radovich S. (2006). Governing Collaborative Governance: Enhancing Development Outcomes by Improving Partnership Governance and Accountability. AccountAbility and the Corporate Social Responsibility Initiative, Working Paper No. 23, Cambridge, MA: John F. Kennedy School of Government, Harvard University 


\section{Notes}

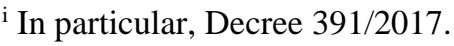

ii Rheingold, H. (2002) Smart Mobs: the Next Social Revolution, Basic Books, Cambridge Mass.

iii Despite multiple approaches, we focus on the integrated approach to CSR embedding social, ethical and environmental concerns in the corporate strategy, as part of the core business processes as defined by Freeman et al and in accordance to the EU Directive 95/2014.

iv The Agenda for Sustainable Development, announced by UN in 2015, is a plan of action for people, planet and prosperity. It includes 17 Sustainable Development Goals and related 169 targets - built on the Millennium Development Goals - are integrated and indivisible and balance the three dimensions of sustainable development: the economic, social and environmental. The Goals and targets will stimulate action up to 2030 in areas of critical importance for humanity and the planet: People, Planet, Prosperity, Peace and Partnership.

${ }^{v}$ http://www.un.org/sustainabledevelopment/

vi Directive 2014/95/EU of the European Parliament and of the Council of 22 October 2014 amending Directive 2013/34/EU as regards disclosure of non-financial and diversity information by certain large undertakings and groups. 